\title{
Carriage rates of hepatitis $B$ virus among individuals of different blood group systems and haemoglobin genotype
}

\author{
Abubakar A. ABDULAZEEZ ${ }^{1 *}$, Ameen NIMAT ${ }^{2}$ and Babatunde K. SHOLA ${ }^{1}$ \\ ${ }^{1}$ Department of Biosciences and Biotechnology. College of Pure and Applied Sciences, \\ Kwara State University, Malete, Nigeria. \\ ${ }^{2}$ University Health Centre, Kwara State University, Malete, Kwara State, Nigeria. \\ *Corresponding author: E-mail: abuazeez1962@yahoo.com; Phone: +2348053283469
}

\begin{abstract}
The study was conducted between September 2012 and May 2013, to determine the frequency of hepatitis B virus carriage among apparently healthy individuals of different blood groups and haemoglobin genotypes. Nine hundred and eighty (980) students and staff comprising of males and females, aged 15-39 years, participated in the study. Five millilitres of blood sample was collected, $3 \mathrm{ml}$ of which was put in a plain container for hepatitis B screening, while $2 \mathrm{ml}$ was put into anti-coagulated container for blood group and haemoglobin electrophoresis. Using hepatitis B immunoassay strip (Global source, Shenyang LTH Tech, China), hepatitis status of each subject was determined; blood group was determined using tube agglutination method, while haemoglobin genotype was determined by electrophoresis method. The overall sero-prevalence recorded in this study was $6.94 \%$. Assessing the infection rate with respect to age and blood group, 15-19 year bracket has the highest rate $18(1.86 \%)$ and it was recorded among blood group individuals. Statistical analysis by Chi Square showed no significant difference in the rate of hepatitis B carriage with respect to ABO blood grouping system $\left(\mathrm{X}^{2}=0.3412, \mathrm{P}>0.05\right)$. The distribution of viral carriage rate among the Rhesus $\mathrm{D}$ positive individuals was statistically higher than the rate in Rhesus $\mathrm{D}$ negative subjects $\left(\mathrm{X}^{2}=4.321, \mathrm{P}<0.05\right)$. Higher frequency of the carriage was also recorded among the females $37(3.78 \%)$ than the males $31(3.16 \%)$. While $\mathrm{Hb}$ - AA individuals had the highest rate of $50(5.10 \%)$ of carriage, there was no case of infection among individuals with $\mathrm{Hb}-\mathrm{SS}, \mathrm{Hb}-\mathrm{SC}$ and $\mathrm{Hb}-\mathrm{CC}$. Statistically, Chi Square test showed no significant difference in the rate of hepatitis $\mathrm{B}$ infection in relation to haemoglobin genotype $\left(\mathrm{X}^{2}=1.201, \mathrm{P}>0.05\right)$. In conclusion, individuals with pathological genotypes $(\mathrm{Hb}-\mathrm{SS}, \mathrm{Hb}-\mathrm{SC}$, and $\mathrm{Hb}-\mathrm{CC}$ ) were hepatitis $\mathrm{B}$ sero-negative. Also, the study recorded a significant link between hepatitis B and Rhesus D blood group system. Further investigation is recommended using more sensitive techniques to corroborate the present findings.
\end{abstract}

(C) 2014 International Formulae Group. All rights reserved.

Keywords: Hepatitis B virus, carriage rates, blood group systems, genotypes.

\section{INTRODUCTION}

The term hepatitis virus is usually used to describe infections caused by agents whose primary tissue of tropism is the liver (Beasley and Hwang, 1999; Lok, 2002). Hepatitis B virus is one of the major health priorities. An estimated 600,000 people die each year because of the acute or chronic consequences of hepatitis B while most of the cases are asymptomatic and more than 350 million people are chronic carriers of the virus worldwide. When tests of carriage of HBV became 
widely available, chronic carrier states were found in many regions of the world (Lavanchy, 2004; Shepard et al., 2006).

Hepatitis B virus is a common cause of liver cirrhosis and hepato-cellular carcinoma ( $\mathrm{Li}$ et al., 2012) and it is endemic in developing region with large populations such as in Sub-Saharan Africa (Jinlin et al., 2005). In some tropical countries, a report indicated that hepatitis $\mathrm{B}$ prevalence ranged between $5 \%$ and $15 \%$ while the global estimate of people with the infection is about 2 billion (Mandell, 2009; Abdulazzez et al., 2008). It was also reported that $15-40 \%$ of $\mathrm{HBV}$ infected patients develop complications (WHO, 2000) and 500, 000 to 1.2 million people die of HBV infection annually (Lok, 2002; Chuckwurah and Nueli, 2006).

Haemoglobin genotype is defined as variants of haemoglobin when blood is subjected to electric field. $\mathrm{Hb}-\mathrm{A}$ is the fastest of the commonest variants, followed by $\mathrm{Hb}-\mathrm{S}$ and $\mathrm{Hb}-\mathrm{C}$ in that other. Genotype can be pathological, trait or normal depending on the types of haemoglobin inherited. Inheritance of similar pathological haemoglobin from both parents lead to homozygous pathological haemoglobin such as $\mathrm{Hb}-\mathrm{SS}$ and $\mathrm{Hb}-\mathrm{CC}$ while inheritance of dissimilar pathological haemoglobin from both parents gives rise to heterozygous pathological haemoglobin such as $\mathrm{Hb}-\mathrm{SC}$ and $\mathrm{Hb}-\mathrm{SD}$. A trait is otherwise known as carrier. It is a heterozygous combination of pathological haemoglobin from one patient and normal haemoglobin from the other such as $\mathrm{Hb}-\mathrm{AS}$ and $\mathrm{Hb}$ - AC. Inheritance of normal haemoglobin from each of the parents result to $\mathrm{Hb}-\mathrm{AA}$.

ABO blood group system was the first human blood group system to be discovered (Abdulazeez et al., 2008). It is made up of A and $\mathrm{B}$ antigens that determine the types of the blood group. Individuals with both antigens in their red blood cells are said to belong to blood group $\mathrm{AB}$, while those with only $\mathrm{A}$ antigen belong to group $\mathrm{A}$ and those with $\mathrm{B}$ antigen only are in group B where as individuals with neither of the antigens belong to blood group O. Rhesus blood group is another crucial blood group system next to $\mathrm{ABO}$ system in blood transfusion. Rhesus D is more prevalent than Rhesus $\mathrm{C}$ and $\mathrm{E}$ in tropical countries (Abdulazeez et al., 2008; Ukaejiofo and Nubila, 2006). Individuals with dominants Rhesus D antigen in their blood are said to be Rhesus D positive while those with recessive antigen are Rhesus $D$ negative.

Many reports in the past had indicated links between some diseases and blood group systems (Mandell, 2009; Li et al., 2012). In a research conducted by Behal et al. (2010), ABO blood group system was linked with hepatocellular carcinoma while Wang et al. (2012) reported an association between blood group A, hepatitis $\mathrm{B}$ and cancer of the pancreas. In another study, stomach cancer was reported to have a higher prevalence among blood group A population than the rest of ABO blood groups (Mahoney, 1999). Similarly blood group $O$ individuals were reported to be more prone to peptic ulcer diseases due to lack of $\mathrm{N}$ - acetyl- glucosamin necessary for the development of mucosa lining of their alimentary canal (Omoregie et al., 2002). This study therefore, was focused on assessment of any link between hepatitis B virus, blood group systems and haemoglobin genotypes.

\section{MATERIALS AND METHODS}

Study population

The study was conducted between September 2012 and May 2013 on nine hundred and eighty samples from apparently healthy students and staff of Kwara State University, Malete, who were on in the routine medical check - up at the University's Health Centre. The subjects composed of males and females aged $15-39$ years. Before sample collection, approval was obtained from Research and Ethics committee of Kwara State University in accordance with Helsinki Declaration Guidelines. Consent of 
all participants was sought and obtained as only volunteers participated in the study.

\section{Collection, handling and processing of specimens}

Five millilitres of blood samples were collected from each of the study subjects. Three millilitres of the specimen were put in plain specimen containers for Hepatitis B virus screening while the remaining 2 millilitres was put in Ehtylene DiamineTetra-acetic Acid (EDTA) containers and mixed properly to prevent clotting before using for grouping and genotype. Commercial Hepatitis B rapid chromatographic immunoassay strip (Global source, Shenyang LTH Tech, China 130033) was employed in the study.

The clotted blood samples were spun at 2,000 revolutions per minute for 2 minutes, sera collected and screened for hepatitis B surface antigen using the procedure described by the manufacturer as follows: Each test strip was dipped into a serum sample up to the marked level on the strip, removed immediately and kept on the laboratory work bench for two minutes before reading and interpretation. Presence of double line on the strip indicates positive result while single line implies absence of hepatitis B surface antigen (Negative). The anti-coagulated blood was used for blood grouping and haemoglobin electrophoresis. Tube method of grouping was employed but all cases of negative results were further confirmed by another tube method using Anti-human globulin (AHG) as previously described technique by Cheesbrough (2002). Haemoglobin genotype of the samples was determined using electrophoresis machine (DY 300, India). The procedure for routine electrophoresis described by Ochei and Kolhatkar (2007) and later by Ramnik and Sood (2009) was followed.

\section{Statistical analysis}

Data obtained from the tests were analyzed with SPSS version 17 software of computer (SPSS Inc. USA). The test for significance was performed using Chi Square statistical analysis for hepatitis B serodistribution in relation to haemoglobin genotypes and blood groups. Statistical difference was interpreted based on $95 \%$ confidence level $(\mathrm{P}=0.05)$.

\section{RESULTS}

Table 1 depicts the distribution of Hepatitis B infection among $\mathrm{ABO}$ blood group system in relation to age and gender of study subjects while Figure 1 indicates the overall frequency of the HBV carriage in relation to blood group. Highest seroprevalence of HBV $38(3.88 \%)$ was recorded within the age bracket $15-19$ years while no HBV infection was recorded within the age 30-39 years. Break down of the infection rate with respect to blood group within the age group $15-19$ years shows highest $18(1.83 \%)$ prevalence among blood group $\mathrm{O}$ while the least $1(0.11 \%)$ was recorded among the subjects with blood group AB. On the overall, out of 68 recorded seropositive cases in this study, 36(3.68\%), 15(1.53\%), 14(1.43\%) and $3(0.31 \%)$ were recorded among subjects with blood group $\mathrm{O}, \mathrm{B}, \mathrm{A}$ and $\mathrm{AB}$ respectively. Statistical analysis by Chi square shows no significant difference in the frequency of $\mathrm{HBV}$ infection with respect to $\mathrm{ABO}$ blood group $\left(X^{2}=0.2171, P>0.05\right)$. Similarly, the overall distribution of Hepatitis $\mathrm{B}$ virus among female was $37(3.78 \%)$ while it was $31(3.16 \%)$ among their male counterparts.

The frequency of Hepatitis B virus in Rhesus D blood group system with respect to age and gender is as shown in Table 2. Out of the entire 68 seropositive HBV recorded, 61(6.22\%) individuals were Rhesus D positive and $7(0.71 \%)$ were recorded in Rhesus D negative. The highest $36(3.68 \%)$ rate of HBV was recorded among Rhesus $\mathrm{D}$ positive subjects within $15-19$ age bracket where as 
the highest rate of the infection among Rhesus D negative was recorded within the age group 20-24 years. The frequency of the seroprevalence of $\mathrm{HBV}$ among Rhesus D positive individuals is statistically higher than the prevalence Rhesus D negative subjects $\left(\mathrm{X}^{2}\right.$ $=4.321, \mathrm{P}<0.05)$.

The overall distribution of the infection in relation to genotype is as shown in Figure 1. Out of 31(3.16\%) males sero-positive with hepatitis $\mathrm{B}$ virus, $23(2.35 \%) 6(0.61 \%)$ and $2(0.22 \%)$ subjects belong to $\mathrm{Hb}-\mathrm{AA}, \mathrm{Hb}-$
$\mathrm{AS}$, and $\mathrm{Hb}$ - AC respectively similarly, of $37(3.78 \%)$ females seropositive HBV, $27(2.76 \%)$ belongs to $\mathrm{Hb}-\mathrm{AA} 8(0.74 \%)$ to $\mathrm{Hb}-\mathrm{AS}$, while $2(0.22 \%)$ belong to $\mathrm{Hb}-\mathrm{AC}$ respectively. There was no case of seropositive reaction among individuals with $\mathrm{Hb}-\mathrm{SS}, \mathrm{Hb}-\mathrm{SC}$ and $\mathrm{Hb}-\mathrm{CC}$. Statistically, Chi. Square test showed no significant difference in the distribution of the viral infection by haemoglobin genotype $\left(\mathrm{X}^{2}=1.201, \mathrm{P}>0.05\right)$.

Table 1: Distribution of Hepatitis B infection among ABO blood groups by age and gender.

\begin{tabular}{|c|c|c|c|c|c|}
\hline \multirow{2}{*}{$\begin{array}{l}\text { Age } \\
\text { Group }\end{array}$} & \multicolumn{2}{|c|}{ Infection rate $(\%)$} & \multicolumn{3}{|c|}{ ABO Blood Groups system (\%) } \\
\hline & $n=980$ & $\mathbf{A}$ & B & AB & $\mathbf{O}$ \\
\hline $15-19$ & $38(3.78)$ & $9(1.00)$ & $10(1.1)$ & $1(0.10)$ & $18(1.84)$ \\
\hline $20-24$ & $27(2.76)$ & $5(0.91)$ & $4(0.48)$ & $1(0.10)$ & $17(1.73)$ \\
\hline $25-29$ & $3(0.31)$ & $0(0.00)$ & $1(0.10)$ & $1(0.10)$ & $1(0.1)$ \\
\hline $30-34$ & $0(0.00)$ & $0(0.00)$ & $0(0.00)$ & $0(0.00)$ & $0(0.00)$ \\
\hline $35-39$ & $0(0.00)$ & $0(0.00)$ & $0(0.00)$ & $0(0.00)$ & $0(0.00)$ \\
\hline Total Gender & $68(6.94)$ & $14(1.43)$ & $15(1.53)$ & $3(0.31)$ & $36(3.69)$ \\
\hline Male & $31(3.16)$ & $6(0.61)$ & $7(0.71)$ & $1(1.1)$ & $17(1.73)$ \\
\hline Female & $37(3.78)$ & $8(0.82)$ & $8(9.82)$ & $2(0.22)$ & 19(1.99) \\
\hline Total & $68(6.94)$ & $14(1.43)$ & $15(10.53)$ & $3(1.32)$ & $36(3.72)$ \\
\hline
\end{tabular}

$\mathrm{n}=980$ which is the total number of subjects examined.

Table 2: Frequency of Hepatitis B viral infection in Rhesus D blood group system according to age and gender.

\begin{tabular}{lccc}
\hline Age Group & Infection rate (\%) & Rhesus D Positive (\%) & Rhesus D Negative (\%) \\
\hline $15-19$ & $38(3.78)$ & $36(3.37)$ & $2(0.22)$ \\
$20-24$ & $27(2.76)$ & $23(2.35)$ & $4(0.43)$ \\
$25-29$ & $3(0.31)$ & $2(0.22)$ & $1(0.11)$ \\
$30-34$ & $0(0.00)$ & $0(0.00)$ & $0(0.00)$ \\
$35-39$ & $0(0.00)$ & $0(0.00)$ & $0(0.00)$ \\
Total Gender & $\mathbf{6 8}(6.94)$ & $\mathbf{6 1}(\mathbf{6 . 2 2})$ & $\mathbf{7 ( 0 . 7 2 )}$ \\
Male & $31(3.16)$ & $29(2.96)$ & $2(0.22)$ \\
Female & $37(3.78)$ & $32(3.29)$ & $5(0.51)$ \\
Total & $\mathbf{6 8}(\mathbf{6 . 9 4})$ & $\mathbf{6 1}(\mathbf{6 . 2 2})$ & $\mathbf{7 ( 0 . 7 2 )}$ \\
\hline
\end{tabular}




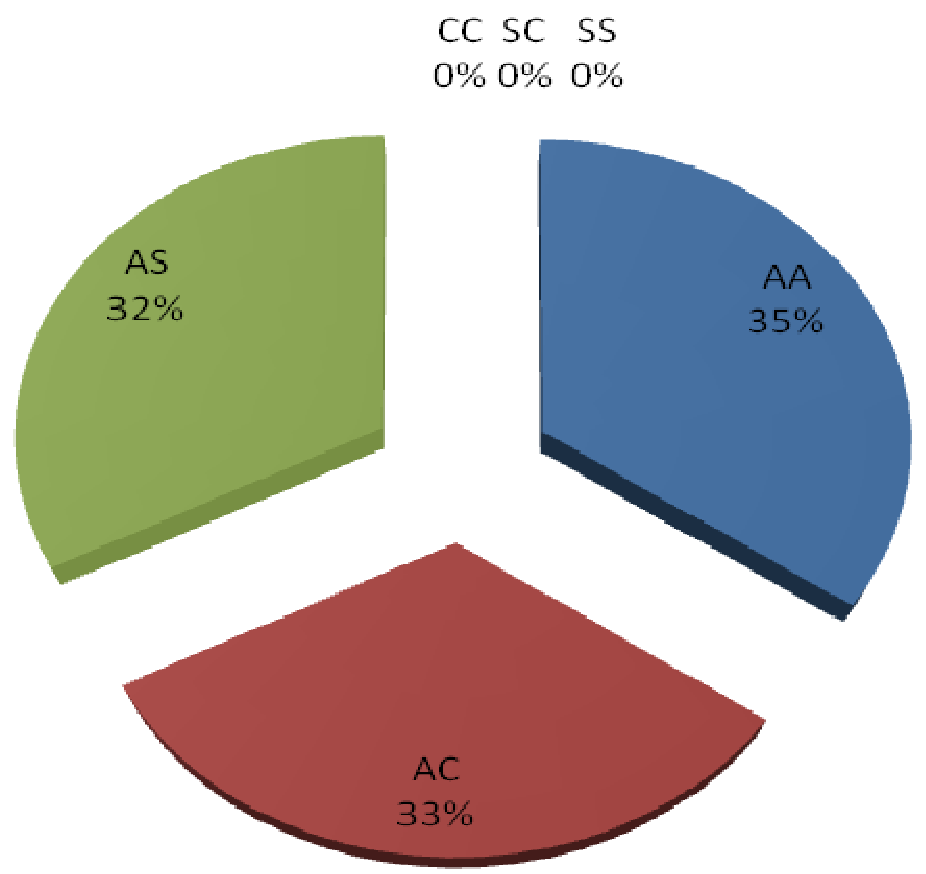

Figure 1: Overall distribution of Hepatitis B viral infection in relation to Haemoglobin genotype.

\section{DISCUSSION}

Although there are several methods such as radioimmunoassay, Enzyme Linked Immunosorbent Assay (ELISA) and Polymerase Chain Reaction (PCR) that can be employed to detect hepatitis B surface antigen in clinical specimens, these methods appear expensive to acquire in most laboratories in developing countries. Rapid immunoassay technique, being more frequently employed in this part of the globe, was therefore used for this study.

Our findings revealed a worrisome rate (6.94\%) of hepatitis B infection among apparently healthy individuals in a university community. This rate calls for concern, considering the fact that the result was obtained within an academic institution that is expected to be more enlightened on health education and prevention against communicable and non-communicable diseases. In line with our result was that of Jinlin et al. (2005) that recorded a high seroprevalence of $\mathrm{HBV}$ of $7.0 \%$ among asymptomatic carriers. However, a low seroprevalence rate of $2.14 \%$ was reported by Alavian et al. (2008) and Nokhadian et al. (2009) in Iran. The reason for the variation in the findings could probably be due to differences in geographical region, methods of viral detection and exposure to the virus. While a rapid chromatographic immunoassay strip was used in this present study, Enzyme Linked Immunosorbent Assay (ELISA) was employed in the previous study. However, the reason for the high rate of hepatitis $B$ infection recorded in this study especially within age bracket 15-29 years could not be ascertained but a previous finding by Yusuf et al. (2009) had associated this age group with hepatitis B and HIV infections.

Judging from the present findings, Rhesus D negative blood group most especially those that are in blood group $\mathrm{O}$ have lower rate of hepatitis B infection while Rhesus D positive individuals recorded higher rate. The reason for this scenario is not certain but could probably be due to lack of A and or 
$B$ antigens in the blood and ability of the group to stimulate more anti-viral antibodies in Rhesus $\mathrm{D}$ negative individuals hence prevent the viral infection. This observation is in line with findings of Abdulazeez et al. (2008) conducted on association between ABO blood group system and HIV infection in which HIV rate was significantly higher among Rhesus D positive than Rhesus D negative individuals.

The age related distribution of the infection revealed that as the age of the subjects increases, the frequency of infection decreases with the highest rate $(3.88 \%)$ recorded within the youngest age bracket 15 19 years, followed by $2.76 \%$ in $20-24$ years age bracket while no infection was recorded among the subjects within age - group $30-34$ years and 35-39 years. The possible explanation for this trend is probably that at younger age the subjects could be more sexually active than in the old age making the younger group more at high risk than their older counterparts. Statistically, however, there was no significant difference in the distribution of the infection by age $\left(\mathrm{X}^{2}\right.$ $=0.9430, \mathrm{P}>0.05$ ).

Similarly, when the frequency of the carriage of $\mathrm{HBV}$ was assessed in relation to gender, higher rate of $(3.78 \%)$ was recorded among the females than their male counterparts with $3.16 \%$ seroprevalence. According to the report of Yusuf et al. (2009), in a similar work, the variation could probably be attributed to difference in anatomical structure of genito-urinary tract which makes females more pre-disposed to sexually transmitted infections. However, the study showed no significant difference statistically in the distribution of the infection according to gender $\left(\mathrm{X}^{2}=0.5532, \mathrm{P}>0.005\right)$.

\section{Conclusion}

In the overall, the sero-prevalence of hepatitis B infection among asymptomatic individuals in the university community investigated was $6.94 \%$. This rate was quite significant and calls for concerted efforts in creating awareness that will prevent further spread. Interestingly, individuals with pathological genotypes $(\mathrm{Hb}-\mathrm{SS}, \mathrm{Hb}-\mathrm{SC}$, and $\mathrm{Hb}-\mathrm{CC}$ ) were not affected by the virus. Further investigation is therefore suggested to document any scientific explanation for this scenario. Lastly, the study recorded a significant link between hepatitis B and Rhesus D blood group system. We recommend further studies using more sensitive techniques to corroborate the present findings.

\section{REFERENCES}

Abdulazeez AA, Alo EB, Rebecca SN. 2008. Carriage rate of Human Immunodeficiency Virus (HIV) infection among different $\mathrm{ABO}$ and Rhesus groups in Adamawa state Nigeria. Biomedical Research, 19(1): 41 -44 .

Alayan SM, Hajariazdeh B, Ahmadzad A, Kabir M, Bagheri L, K 2008. Hepatitis B Markers in Iran: A Systemic Review. Hepat. Mon., 8: 281-294.

Beasley RP, Hwang LY. 1999. Overview on the epidemiology of hepato cellular carcinoma. 532. In Viral Hepatitis and Liver Disease, Hollinger FB, Lemon SM, Margolis HS (eds). William and Wilkins: Baltimore; 124-356.

Cheesbrough M. 2002. Laboratory Practise in Tropical Countries (vol 2). Edition Cambridge: UK; 320-450.

Chuckwurah EF, Nneli JR. 2006. Prevalence of Transfusion transmissible infectious disease markers among blood donors in a South-Eastern State of Nigeria. Lab News, 1: 9 - 11.

Jinlin H, Zhihua L, Fan G. 2005. Epidemiology and Prevention of Hepatitis B virus infection. Int Jour. Med Sci., 2(1): 50 - 57.

Lavanchy D. 2004. Hepatitis B virus epidemiology, disease burden, treatment and current emerging prevention and control measures. J. Viral Hepatitis, 11: 97-107.

Li Q, Yu CH, Yu JH, Liu L, Xie SS. 2012. $\mathrm{ABO}$ blood group and the risk of 
hepatocellular carcinoma: A case-control study in patients with chronic hepatitis B. PLoS One, 7(10): 1371

Lok AS. 2002 Chronic hepatitis B. N. Engl. J. Med., 346: 1682-1683.

Mahoney FJ. 1999. Update on diagnosis, management, and prevention of hepatitis B virus infection. Clin. Microbiol. Rev., 12: 351-366.

Mandell GL. 2009. Principles and Practice of Infectious Disease (7th edn). Churchill Livingstone: USA.

Nokhadian Z, Kassaian N, Ataei B, Jaradi AA, Shoaei P, Farajzadegan Z, Adibi P. 2009. Hepatitis B Markers in Isfahan, Central Iran; A Population-Based Study. Eepat Mon., 9: 12-16.

Ochei J, Kolhatkar A. 2007. Medical Laboratory Science: Theory and Practice $\left(6^{\text {th }}\right.$ edn). Tata McGrw-Hill Publishing Company Limited: New Delhi, India; 160-162.

Omoregie R, Ogefere H, Omokaro E, Omorogbe E. 2002. Distribution of ABO and Rhesus blood group and Haemoglobin Phenotypes among tuberculosis patients in Benin - city, Nigeria Jour. Med. Lab Sci., 11: 68 - 70.

Ramnik J, Sood A. 2009. Introduction to Medical Laboratory Technology:
Methods and Interpretations. New Edition Jay Pee Publications: India; 2571.

Shepard CW, Simard L, Finelli AE, Fiore, Bell BP. 2006. Hepatitis B virus infection: Epidemiology and vaccination. Epidemiol. Rev., 28: 112125.

Ukaejiofo EO, Nubila T. 2006. Association between ABO, Rhesus blood group systems and haemoglobin genotype among confirmed HIV/AIDS - TB co - infected patients in Enugu Urban, Nigeria. West African Journal of Medicine, 25(1): 61 - 64 .

Wang DS, Chen DL, Ren C, Wang ZQ, Qiu MZ. 2012. ABO blood group, hepatitis $B$ viral infection and risk of pancreatic cancer. Int. J. Cancer., 131: 461-468.

WHO. 2000. Hepatitis B: World Health Organization Fact Sheet 204. World Health Organization.

Yusuf AA, Nbinkar DL, Abdulazeez AA. 2009. Seroprevalence of HIV and Hepatitis B infection among blood donors in Yola Adamawa State. Int. Jour. Nat. Appl. Sci., 3(1): 139 - 142. 